\title{
First level library and/or information science qualifications at South African universities and technikons: a comparative study of curricula'
}

\author{
J. Raju \\ Department of Library and Information Studies, Durban Institute of Technology \\ M.L. Sultan Campus, P.O. Box I334, Durban 4000, Republic of South Africa \\ jayar@dit.ac.za
}

\begin{abstract}
Received: $5^{\text {th }}$ May 2003
Revised: 12 January 2004

The article focuses on some of the findings from a comparative study of first level library and/or information science qualifications offered at South African universities and technikons. A survey was used through self-administered questionnaires to solicit the views of employers, past students and educators in the LIS field regarding the qualifications and their relevance to the LIS services work environment. The study confirms that the university Post-graduate Diploma in Library and/or Information Science and the B.Bibl. (or equivalent four-year university degree) are established professional LIS qualifications in South Africa. While the technikon ND: LIS is generally viewed as a paraprofessional qualification, LIS services employers are not using this qualification in its paraprofessional context. The technikon B.Tech.(LIS) cannot be viewed as a professional LIS qualification as it lacks general education and furthermore, it is a qualification in the hierarchy of paraprofessional LIS qualifications that runs parallel to the professional LIS career path. The study suggests that the professional body, educators, employers and graduates and diplomates in the LIS field in South Africa have specific roles to play in ensuring understanding that LIS professionalism and paraprofessionalism are alternative career paths, each with their own career progressions and with valuable roles to play in LIS services.
\end{abstract}

\section{Introduction}

There seems to be lack of clarity among the majority of people associated with library and/or information services (LIS services) ${ }^{2}$ as to the relationship between university and technikon first level library and/or information science (LIS) education and training. LIS educators, as well, need to decide what to teach, at what levels and for what types of posts in the work environment. The situation is aggravated by the fact that technikons in South Africa, which had previously offered non-degree programmes only, have begun to offer programmes leading to degree qualifications. This article reports on some of the findings that emerged from a comparative study of first level library and/or information science qualifications offered at South African universities and technikons. The study hopes to provide guidance to employers, students and educators regarding education and training as well as employment in the library and/or information services field.

The objectives of this article are, firstly, to provide clarity to those currently employed in library and/or information services, those who wish to become library and/or information professionals and those who want to employ library and/ or information professionals as to what type of first level education and training is required for given posts in the LIS services work environment; and secondly, to provide clarity to library and/or information science educators regarding what job specifications they should be targeting in the academic curriculum, especially in view of the seemingly blurred demarcation between university and technikon library and/or information science education. These objectives are addressed/articulated through the following questions: Firstly, what are the job titles and key job tasks or functions of posts in the library and/or information services sector that require knowledge and skills that are imparted by first level library and/or information science qualifications? Secondly, to what extent do the various first level library and/or information science programmes currently being offered in South Africa meet the job tasks or functions of posts that require the knowledge and skills that are generally imparted by first level library and/or information science qualifications?

I. This article reports on some of the findings that emerged from the following doctoral study: Raju, J. 2002. First level library and/or information science qualifications at South African universities and technikons : a comparative study of curricula. PhD thesis, University of Natal, Pietermaritzburg.

2. In order to facilitate the write-up of this article, 'library and/or information services' is abbreviated in certain places as LIS services and 'library and/or information science' is abbreviated as LIS. 


\section{Definitions of concepts}

Library and/or information services

The term library and/or information services, in this article, refers to services provided by libraries as well as by other information supplying agencies and which facilitate the management and use of recordable information and knowledge (American Library Association 1992:I). This term is, for the sake of brevity, abbreviated in certain places as LIS services.

\section{Library and/or information science}

This term refers to the discipline or branch of learning of library and information science/studies as well as that of information science/studies. This discipline is generally concerned with recordable information and knowledge, and the services and technologies to facilitate their management and use (American Library Association 1992: I). Library and/or information science is, again for the sake of brevity in this article, abbreviated in certain places as LIS.

First level library and/or information science qualification

A first level library and/or information science qualification is a beginning LIS qualification that affords an individual entry into the LIS services work environment where the work can be at the professional or at the paraprofessional level. This is different from a first level professional library and/or information science qualification.

First level professional library and/or information science qualification

This is a beginning LIS qualification that affords an individual entry into the LIS services work environment at a professional level. Another term that requires clarity is 'library and/or information professional'.

Library and/or information professional

The library and/or information professional works at the professional level, engages in high level planning, development, design, evaluation and therefore needs to be competent in skills such as analysis, evaluation and synthesis (Kerkham 1988: 7). In the library context the professional is often referred to as a librarian. In other information contexts professionals are referred to as documentalists, records managers, archivists, information scientists and museologists. The library and/or information professional is believed to be different from the library and/or information paraprofessional.

Library and/or information paraprofessional

The library and/or information paraprofessional engages in the application of known techniques and principles, in the organisation and supervision of systems designed by professionals and therefore needs to be competent in skills such as comprehension, application and communication. In the library context the paraprofessional is commonly referred to as a library technician, or sometimes as a library assistant, and performs a supporting role alongside the professional librarian (Kerkham 1988:7-8).

\section{Methodology}

The research design in this study involved two crucial aspects, that is, an extensive review of related literature and a survey of relevant populations by means of mailed, self-administered questionnaires to facilitate relevant data collection. The review of related literature was necessary to locate the study in its proper context by identifying and analysing various issues in the literature that are related to the study.

In order to fulfil a comparative study of first level library and/or information science qualifications offered at South African universities and technikons, it was necessary to survey the views of past students, employers and educators in the LIS field regarding these qualifications and their relevance to the LIS services work environment. The self-administered questionnaire was selected as the data-gathering instrument for this study.

Three different questionnaires were designed. There was a questionnaire for library and/or information science graduates and diplomates from universities and technikons, a questionnaire for library and/or information services employers and a questionnaire for library and/or information science educators at universities and technikons. The purpose of the questionnaires was to gather data on the views of past students (that is, graduates and diplomates), employers and educators in the LIS field regarding first level LIS qualifications offered at South African universities and technikons and their relevance to the LIS services work environment. While there were some questions that were common to all three questionnaires, thus allowing for comparisons during the analysis stage of the research, in large part each questionnaire was specifically targeted at a particular population.

Titles and brief descriptions of the various modules offered in the different first level LIS programmes presented in the questionnaires were gleaned from information available from LIS academic departments' web sites, departmental handbooks and most recent prospectuses of universities and technikons. Among the various LIS academic departments there are slight differences in terminology used in academic programmes, content of instructional offerings, levels at which certain aspects of the programme are offered and other minor differences. For the purposes of the research these minor differences were immaterial as long as all existing modules had been reflected in the questionnaires as being part of 
a programme leading to a first level LIS qualification. The study, and hence the questionnaires, did not include for comment 'odd' first level LIS qualifications offered by individual institutions, for example, the Diploma in Information Science offered by the University of South Africa, the B.Bibl. (Alternative) offered by the University of the Western Cape and specialist first level LIS qualifications offered by certain institutions only, such as the Post-graduate Diploma in Records and Archives Management offered by the University of Natal. Instead the focus was on first level LIS qualifications commonly offered by LIS education and training departments or programmes throughout the country.

The survey part of the study had three distinct target populations, that is, past students, employers and educators in the LIS field. The way in which each of these three populations was dealt with in the survey needs to be explained.

It was decided to survey past students who had graduated in the last five years with first level LIS qualifications and who are currently employed in library and/or information services. Five years was used as the cut-off mark for past students as it is generally agreed that it takes about five years for one to establish oneself in a particular work environment and to reach a point at which one has firm ideas and opinions about a particular work environment and issues relating to it. It was necessary for the participant in the survey to be employed in a LIS service in order to contribute views or opinions regarding first level LIS qualifications and their relevance to the LIS services work environment. Past students in the survey included first level LIS qualification graduates and diplomates from universities and technikons in South Africa. Due to the absence of a reliable sampling frame as well as the fact that it is generally difficult to trace diplomates and graduates, it was decided not to extract a sample but to target this population generally or purposively via existing LIS services requesting them to distribute the survey instrument among staff who had graduated with first level LIS qualifications in the last five years.

LIS services employers were also a target population in the survey. Employers here included heads and deputies, where applicable, of LIS services, as it is believed that even though the 'employer proper' may be some larger body under which the LIS service falls, for the purposes of the study heads and deputies were regarded as employers as they occupy employee recruitment and policy or decision-making positions in organisations. The survey included heads and deputies of provincial library services, major public library services, academic libraries including both university and technikon libraries, the National Library of South Africa, major special libraries or information services, major museum libraries, and national and provincial archives. The author was confident that this grouping provided an adequate coverage of the major LIS services in the country. School libraries were not included in the survey as they are generally considered to be a 'special breed'. The Department of Education generally requires specialised training for librarians wishing to work in school libraries and this generally includes a teaching qualification together with a degree or diploma specialising in school libraries. College libraries were also not included in the survey as this is a large and unwieldy sector that is still in the process of being consolidated into the higher education as well as the further education sectors in South Africa. The author was confident that academic libraries were more than adequately covered by the more established university and technikon sectors. It was decided that in the bigger LIS services it would not just be heads and deputies who would be surveyed, but senior managers as well who are very often involved in employee recruitment and other decision-making. The largeness of the service necessitated this, as well as the fact that heads or deputies, for some reason, might not be able to participate in the survey. This option served to ensure adequate input into the study from the larger LIS services that are generally big employers of LIS graduates and diplomates. It was decided not to draw a sample from this population but to target the whole population of heads, deputies and senior managers of LIS services. The motivation for doing this, despite increased costs in terms of time, printing and mailing, is the general tendency towards low returns on mailed, self-administered questionnaires. The author wished to ensure as many returns from as many LIS services as possible.

Library and/or information science (LIS) educators formed the third and final target population group in the study. It was necessary, too, to gather their views regarding first level LIS qualifications offered at South African universities and technikons and their relevance to the LIS services work environment. Currently there are thirteen LIS education and training departments or programmes based in universities and technikons in South Africa. Information gleaned from academic departments' web sites as well as direct contact with the departments themselves revealed that at the time of conducting the survey (April/May 2002) there was a total of sixty-eight full-time educators in these various departments or programmes. The author believed that this population was sufficiently manageable to be surveyed and that there was no need to draw a sample.

While the return rate of questionnaires from employers and past students (I7\% and $15 \%$, respectively, of the total number of questionnaires sent out - 455 and 554, respectively) may be considered to be low, there was input from significant quarters of these populations that needed to be analysed and reported. There was an overall response rate of $52 \%$ from the educator population, and according to Babbie (1990: 182), 'a response rate of 50 percent is generally considered adequate for analysis and reporting'.

SA JnI Libs \& Info Sci 2004, 70(I) 
All three of the questionnaires used in the study consisted of structured items and unstructured items. Two of the questionnaires had a single item each that requested documentary data in the form of job contents of particular job titles to be attached to completed questionnaires. With regard to responses to structured items, numerical coding was used to reorganise data collected in order to make it suitable for computer processing as the computer can 'quickly and accurately process data and correlate variables' (Hult 1996: 63). The responses to unstructured items as well as the documentary data (job contents attached to certain completed questionnaires) were subjected to content analysis. In the case of responses to unstructured items in the questionnaires as well as the 'other' category of structured items, the contents of these responses were analysed and reduced to common 'themes', which were then coded. According to Neuman (1997: 272-273) this coding 'turns aspects of content that represent variables into numbers' which are entered into a computer for statistical analysis that allows the information in the content being analysed to be presented in the form of tables or graphs so that certain trends or patterns can be identified. Neuman sees this as a quantitative version of content analysis. With regard to the job contents, what Neuman terms as an interpretive or qualitative version of content analysis was adopted. Data was reduced to key functions under specific job titles in order to identify patterns or trends. Thus the raw data contained in the three sets of completed questionnaires were prepared for analysis by means of numerical coding as well as quantitative and qualitative content analysis.

The three data sets for the three sets of completed questionnaires were analysed statistically. Descriptive analysis of the data (mainly frequency and percentage distributions), using the Statistical package for the social sciences (SPSS), was mostly done. 'Descriptive analysis aims to describe the data by investigating the distribution of scores on each variable, and by determining whether the scores on different variables are related to each other' (Durrheim 1999: 101). The results of the qualitative content analysis were simply attached to the relevant data set for use during the presentation and interpretation of results stage.

The data collection instruments, that is, the three questionnaires, generated the data required for the study, which together with the review of related literature enabled the author to address the research questions generated for the study. Descriptive statistical analysis as well as content analysis of data generated by the questionnaires were considered appropriate and adequate for the study.

While the return rates of questionnaires, especially from LIS services employers and past students, might be considered low for generalisations to be made regarding the views of these populations as a whole on first level LIS qualifications offered at South African universities and technikons and their relevance to the LIS services work environment, they were still useful in revealing important views on this issue among these populations and thus analysis and reporting here were considered important.

\section{Results and discussion}

I. The following findings and discussions are relevant to the Research question: What are the job titles and key job tasks or functions of posts in the library and/or information services sector that require knowledge and skills that are generally imparted by first level library and/or information science qualifications?:

I.I National Diploma: Library and Information Studies (ND: LIS) qualification

While a variety of job titles were forwarded by employers with respect to staff members holding the technikon ND: LIS, the job titles library assistant and senior library assistant seem to be most common in LIS services among these staff members. Findings in the survey of past students concurred with these findings in the survey of employers.

Job titles and contents provided by employers revealed that there seems to be much inconsistency in the use of terminology in the job titles assigned to individuals holding this level of qualification as evident in the use of job titles such as 'library assistant', 'cataloguing assistant', 'assistant librarian' and 'junior librarian'. In some cases the terminology used seem to be determined by the LIS services context in which the job is located. In other cases it might simply be a reflection of preference for the use of certain job titles or perhaps the need to follow job titles used by the parent organisation of which the library or information service is a part. The literature (Gillen 1995; Rodgers 1997; Froehlich 1998) does indicate that this inconsistency in the use of terminology in job titles at this level of qualification is a general trend. It is interesting to note, and as pointed out by Van Aswegen (1997), that the job title 'library technician' that is in common use for this level of qualification in other parts of the world, does not seem to be used in South Africa. Instead the term 'library assistant' seems to be in common use.

Job contents provided by employers revealed that the ND (National Diploma): LIS is being utilised by many LIS services employers as a qualification requirement for support positions, especially that of senior library assistant. This concurs with the finding that the job titles 'library assistant' and 'senior library assistant' seem to be common in LIS services for staff members holding an ND: LIS. These job contents also revealed that this qualification requirement seems to be particularly the case in the circulation function of LIS services. The dominance of technical aspects of the service 
seems to necessitate the need for technically oriented paraprofessional staff and the ND: LIS, as revealed in the literature (Kerkham 1988; Nettlefold 1989; Halsted and Neeley 1990), provides very much this type of education and training. Furthermore, a key function under 'senior library assistant' job titles provided by employers seems to be supervising staff and processes in the section. The literature (Kerkham 1988; Nettlefold 1989; Halsted and Neeley 1990) does reveal that one of the many tasks generally assigned to paraprofessionals is supervision of a branch, department or section of a library system. Job contents provided by employers suggest that some LIS services employers view the ND: LIS as appropriate education and training for the supervisory function in LIS services, and this is very much in keeping with international trends regarding LIS services paraprofessionals.

Both employers and educators surveyed indicated that the posts of library assistant, senior library assistant (including other titles used to designate senior categories of library assistants) and library technician are largely the types of posts that should constitute paraprofessional job titles. Furthermore employers surveyed have indicated that they would place individuals holding the ND: LIS in paraprofessional entry-level posts, thus reaffirming that the ND: LIS has become established as a paraprofessional LIS qualification in South Africa as revealed by the SAILIS Proposed guidelines for undergraduate career training (South African Institute for Librarianship and Information Science (SAILIS) 1996) and by job contents provided by employers.

It is evident from these findings that while in the early years of the ND: LIS diplomates experienced problems in LIS services employers seeing this qualification as a paraprofessional qualification as reported by Van Aswegen (1997), over the years it seems to have become utilised by many LIS services employers as a qualification requirement for what seems to have become known as paraprofessional positions in LIS services, and especially that of senior library assistant. However, it is essential for the author to point out that the problem of a lack of post descriptions to accommodate the qualification pointed out by Van Aswegen (1997), still persists. Employers seem to have gradually recognised the value of this qualification in particular areas of LIS services, for example in the circulation function as pointed out above, but still have made no attempt to create career ladders in LIS service staff structures for paraprofessionals. Instead, they continue to use designations such as library assistant and senior library assistant for which the qualification requirement has traditionally been a matriculation senior certificate. This not only keeps salary structures for a particular category of staff who have received specific LIS education and training that distinguishes them from clerical staff, at the lowest levels in the organisation, but also demonstrates a lack of clarity among LIS services employers that the ND: LIS is a paraprofessional qualification with a distinct career path for the holder of the qualification. According to the literature (Bramley 1975; Bowman 1988; Oberg 1992; Rochester 1997) LIS professional bodies in the United States of America, Canada and Australia officially recognise library technicians as LIS paraprofessional staff with a distinct career structure in LIS services. While LIASA is not a statutory body it can still, by similar action, influence the way employers view this category of staff. Educators too have a role to play here and it is the author's opinion that educators involved with the ND: LIS programme have not sufficiently marketed the qualification among employers as one whose incumbents have specific knowledge and skills and are able to occupy specifically designated paraprofessional posts. ND: LIS diplomates too can help themselves out of this situation by organising themselves into structures such as paraprofessional interest groups, staff associations or even unions that can be used to lobby for career ladders in LIS services as their counterparts have done with much success in the United States of America, Canada and especially Australia (Bowman 1988; Oberg 1992).

I.2 Bachelor of Technology: Library and Information Studies (B.Tech.(LIS)) qualification

While Underwood and Nassimbeni (1996) point out that there is uncertainty regarding whether the B.Tech. (LIS) should be regarded as a professional LIS qualification, findings in the survey of employers point to a trend towards the acceptance by some LIS services employers of the B.Tech. (LIS) as a professional LIS qualification warranting the designation of the job title librarian. However, the large percentage of employers surveyed $(67.1 \%)$ that indicated that they did not have staff members with the B.Tech.(LIS) qualification points to the uncertainty referred to by Underwood and Nassimbeni (1996) regarding this qualification. It would seem that many LIS services employers are not employing these graduates, as they are unsure about how to view this four-year technikon degree qualification vis-á-vis the four-year university LIS qualifications. Job contents of job titles held by staff members with first level LIS qualifications provided by employers revealed just two or three instances where the B.Tech.(LIS) is made a qualification requirement for specific posts in LIS services. However, where the B.Tech.(LIS) is provided as a qualification requirement, it is done so together with the four-year university LIS qualifications. Job contents provided also revealed that the two or three LIS services that indicated this qualification as a requirement for a professional position appear to be technikon libraries that could possibly be supporting technikon qualifications. It remains to be seen if this spreads to other types of LIS services such as university libraries and public libraries. However, when LIS services employers surveyed were asked in what type of entry-level post they would place individuals holding the B.Tech.(LIS), the majority of respondents indicated that they would place them in professional entry-level posts. The author views uncertainties regarding the B.Tech.(LIS), as pointed out by 
Underwood and Nassimbeni (1996), and uncertainties and inconsistencies regarding this qualification in the findings among employers surveyed, as possibly being the result of a general lack of clarity, especially among employers, on the issue that professionalism and paraprofessionalism are parallel career paths. Each has its own career progression and, as pointed out in the literature (Kerkham 1988; Nettlefold 1989; Horton 1990), the latter is not a step in the direction of professionalism. The author believes that because of the lack of career ladders for paraprofessionals in LIS services as mentioned above, B.Tech.(LIS) graduates are pushing for professional status and equivalence of the B.Tech.(LIS) qualification with the four-year university qualifications which are, in terms of the literature (Musiker 1986; Kerkham 1988; South African Institute for Librarianship and Information Science 1987, 1996) and international trends (Bramley 1975; Stieg 1992; Rochester 1997; Rosenberg 1999), established professional LIS qualifications. In fact the survey of past students has revealed that this lack of career progression for holders of paraprofessional qualifications is a reason given for not pursuing further studies in the LIS field and for general disillusionment with the profession and hence plans to make a career change.

Again, it is perhaps necessary to point out that educators need to play a more concerted role in making both employers and students themselves aware that LIS professionalism and paraprofessionalism are alternative career directions. Possibly once employers are clear about this they would begin to see the value of establishing career progressions for paraprofessionals in their staff structures. Wilson and Hermanson (1998) makes the useful suggestion that students, while still at LIS education and training institutions, should be taught the fundamental difference between professionalism and paraprofessionalism in the LIS services context, so that in the work environment both would be aware of each other's strength and roles and the nature of their working relationship. While it is important that students should be made to understand that paraprofessionalism is not a step in the direction of professionalism but should have its own career progression, it is also important that an education system should allow for articulation between professionalism and paraprofesionalism giving one the opportunity to satisfy certain requirements before 'crossing over' to LIS professionalism if one so desires.

I.3 Post-graduate Diploma in Library and/or Information Science and the Bachelor of Library and Information Science

(B.Bibl.) (or equivalent four-year university degree) qualifications

A significant number of the staff members in LIS services holding the Post-graduate Diploma in Library and/or Information Science or the B.Bibl. (or equivalent four-year university degree) seem to be assigned professional posts with job titles such as librarian or senior categories of librarian, subject librarian, and archivist in LIS services. This is not surprising, as these are, according to the literature (Musiker 1986; Kerkham 1988; South African Institute for Librarianship and Information Science 1987, 1996), established professional LIS qualifications in South Africa. Findings in the survey of past students confirm this. Both employer and educator respondents indicated that posts of librarian (including subject librarian, reference librarian and senior categories of librarians such as senior librarian, branch librarian and head librarian or director) are largely the types of posts that should constitute professional job titles.

\section{I.4 Downshifting of LIS services roles}

Both employer and educator respondents indicated job titles such as acquisitions librarian, circulation librarian, serials/ periodicals librarian, cataloguer and systems librarian as professional and paraprofessional job titles, suggesting that these could be professional or paraprofessional job titles in LIS services. According to the literature (Mugnier 1980; Webb 1988; Nettlefold 1989; Johnson 1991; O'Brien and Cowans 1995; Rodgers 1997; Wilson and Hermanson 1998) these are precisely some of the areas that have traditionally been the domain of professional librarians but have now come to be dominated by individuals holding paraprofessional qualifications. Job contents received from employers, too, revealed this. For example, an observation from these job contents is that while cataloguing (including descriptive and subject aspects of cataloguing) is generally seen as a professional LIS services function, aspects of it are done by support staff in LIS services. For example, copy cataloguing that essentially involves downloading cataloguing details from a centralised database is commonly done by library assistants and senior library assistants. This is in keeping with a general trend reflected in the literature cited above, where many tasks traditionally reserved for professionals, that is, librarians, are now being done by paraprofessionals. This is particularly so in those areas of librarianship and information work, for example cataloguing, circulation, acquisitions and periodicals that have become more technical with less need for the interpretive skills of a librarian. It is perhaps this downshifting and resulting blurring of roles, referred to by Oberg (199I, 1992), which leads some employer and educator respondents to argue that there should not be clearly defined professional and paraprofessional job titles in LIS services. The majority of employers and educators surveyed, however, indicated that there should be clearly defined professional and paraprofessional job titles in LIS services. The author would like to suggest that employers should use this natural downshifting of roles, which according to Nettleford (1989) seems to occur as librarianship and information work advances in its professionalism and also as a result of forces such as 
advancing technology, as opportunities to establish paraprofessional post designations and career progressions in their organisations.

2. The preceding discussions have highlighted, and/or raised issues relating to, the job titles and key job tasks or functions of posts that require knowledge and skills imparted by first level LIS qualifications.

The following discussions are relevant to the research question: To what extent do the various first level LIS programmes currently being offered in South Africa meet the job tasks or functions of posts that require the knowledge and skills that are generally imparted by first level LIS qualifications?

It must be pointed out that while respondents were asked to rate the relevance of the modules of first level LIS programmes in terms of their current job environments on the basis of the title of the module and a brief description of it, there were shortcomings here. For example, there was no clear indication as to the depth of knowledge and skills that were taught as well the availability of resources such as library, physical and IT resources to support the teaching, and the competence of the academic staff involved in the programme. While these crucial factors were difficult to reflect in the surveys carried out for the study, the author hoped that the ratings provided would give some indication of the relevance of the various modules to the LIS services work environment and hence reveal certain trends. It should be noted that while the discussions that follow mention titles of modules only (for reasons of space), brief descriptions of the content of these modules are available in the original study (Raju 2002).

2.I ND: LIS programme

Many of the modules in the ND: LIS are considered relevant to the LIS services work environment by both employers and past students surveyed, as they received percentage relevance in excess of $85 \%$. However, both employers and past students believed that the African languages and Afrikaans are not as relevant to their work environments compared to English. With both employers and past students, User Studies I, II and III and Library and Information Technology III' received relatively low percentage relevance possibly pointing to the fact that these modules are aimed at specialised LIS services environments (such as the public library in the case of User Studies and the digitised information environment in the case of Library and Information Technology III) rather than the LIS services environment in general. Human Studies and Literature Studies received relatively low ratings from both employers and past students. These respondents possibly view these modules as being too general and thus somewhat peripheral to the LIS services work environment. While employers considered Psychology in Organisations as not being very relevant to the LIS services work environment, past students considered it to be useful. Some employers and past students surveyed suggested that the African languages and Afrikaans should be made optional modules in the programme and that Human Studies, Literature Studies and User Studies are not relevant to the programme, implying that they should be removed. The author would like to argue that the latter suggestions would be unwise, because while these modules as well as Psychology in Organisations may be considered by some not to be directly relevant to LIS services, they are very useful in providing general education. General education, which according to the literature (Shera 1972; Gates 1976; Wiegand 1986; South African Institute for Librarianship and Information Science 1987, 1996; Robbins 1990; Davidson-Arnott and Kay 1998; Quattrocchi 1999; International Federation of Library Associations and Institutions 2000) and many respondents in the study is essential in the provision of an efficient LIS service, is generally lacking in technikon LIS qualifications.

\subsection{B.Tech.(LIS) programme}

Both employers and past students surveyed considered modules such as Research Methodology, Information Retrieval IV, Library and Information Practice IV and Information Management as being relevant to the LIS services work environment. Modules such as Library and Information Technology IV, Readership for Semi-literates, Children's Library Practice and Book Conservation, that are aimed at specialised library or information environments, received relatively low ratings from both employers and past students. Philosophy of Library and Information Science did not fare well in the percentage relevance among both employers and past students, probably because of the academic nature of the module and its lack of practical relevance to the library and information environment. Again, the author would like to point out the value of such a module as general education, the lack of which is generally viewed as a shortcoming of technikon LIS qualifications. Some past student respondents, quite appropriately, have called for those modules not relevant to the LIS services environment in general but to more specialised environments and ideal for the elective aspects of an academic programme, to be optional.

\subsection{Post-graduate Diploma in Library and/or Information Science programmes}

Most of the modules included in the Post-graduate Diploma programmes at South African universities show a high percentage relevance, thus demonstrating that they are considered by employers and past students surveyed to be very

I. Brief descriptions of these and other modules discussed in this article are provided in the original study (Raju 2002). These are not detailed in this article for reasons of space. 
relevant to the LIS services work environment. One or two modules, again those that are aimed at specialised LIS services environments as well as those of a more general nature and possibly not directly relevant to the LIS services work environment, received relatively lower percentage relevance. These modules included Information and Communication Technologies (generally aimed at a digitised information environment), Records and Documents Management and Information Delivery Systems (modules aimed at more specialised information environments). Information Society, that did not receive as high a percentage relevance, especially from employers surveyed, in comparison to other modules in the Post-graduate Diploma programmes, is more of a general module and perhaps not directly relevant to the LIS services work environment, and may be considered to be somewhat peripheral to the LIS services work environment.

\subsection{B.Bibl. (or equivalent four-year university degree) programmes}

The general trend that revealed itself in the rating of modules by employers and past students surveyed in the other three LIS programmes prevailed with the B.Bibl. or equivalent four-year university programmes as well. Modules that are applicable to all types of library and information environments were generally considered to be very relevant by employers and past students, and received relatively high percentage relevance. Modules of a more specialist nature, such as Educational Information Services in Developing Countries, Children and Youth Library Services, Advanced Classification, Special Cataloguing, Publishing, Printing and the Book Trade and Compilation of Bibliographies, received relatively lower percentage relevance. Once again, modules of a more general nature and not directly relevant to the LIS services work environment, such as Applied Records Studies, were not considered by respondents to be very relevant, and hence received relatively lower percentage relevance. It is interesting to note that Fieldwork or Experiential Learning generally received relatively high percentage relevance, especially from employers, in all the LIS programmes in which it is offered. It is also interesting to note that modules in all of these LIS programmes that involve cataloguing and classification, received relatively high percentage relevance. This concurs with the results of a tracer study by Ocholla (200I: I66) that found that cataloguing and classification, which are sometimes considered by LIS educators to be 'irrelevant' because of easy access to centralised cataloguing services, are considered to be relevant because 'they provide knowledge on analysis and synthesis of information as well as knowledge of the nature and structure of a given information collection'. Both employers and past students surveyed found some of the modules of a specialist nature to be too specialised for a first level LIS programme. Such modules are ideal for the elective aspects of an academic programme and are likely to be offered as such in education and training institutions.

\subsection{Suggestions for aspects to be added to first level LIS programmes}

Both employers and past students surveyed provided numerous suggestions for aspects that should be included in first level LIS programmes. These suggestions are detailed in the original study (Raju 2002). There was a significant amount of overlap in the suggestions made by employers and past students regarding aspects that should be included in first level LIS programmes. For example, budgeting and human resources management have been suggested by both employers and past students surveyed, as being aspects that should receive attention in the various first level LIS programmes. A strong pre-occupation of recent diplomates and graduates with the IT aspects of LIS services was revealed in the suggestion by a number of recent graduates for greater focus on IT aspects such as database management, web design, Internet searching, digital libraries and systems management in especially university based LIS programmes. Perhaps recent graduates are responding to what some employers have cited as a weakness of the university based LIS qualifications, that is, a general lack of IT skills training and not enough emphasis on electronic developments. Information and/or knowledge management has been suggested by both employers and past students surveyed as also being aspects that should receive attention in the various first level LIS programmes revealing the growing importance of these areas in the work place generally and in the LIS services work environment in particular. There have been requests by past students surveyed for an increase in the university based LIS programmes in the amount of time spent doing fieldwork or experiential learning which generally in these programmes is much shorter than in the technikon based LIS programmes by virtue of the different focus (practical focus and theoretical focus) of each of these types of programmes.

These and the many other suggestions made by employers, past students as well as educators for knowledge and skills to be included in first level LIS programmes raises the issue of whether it is possible for LIS departments or programmes to provide education and training at a functional level in all these areas. Only a certain amount of knowledge and skills can be provided in a duration of three or four years. The rest, in the author's opinion, should come from continuing education either provided by employers or taken up on the initiative of the individual in the interest of self-development. Dougherty (1986) has argued that LIS schools and departments cannot be expected to shoulder the entire responsibility for preparing graduates for the work place because the intellectual demands are too diverse and the time available to educators too short. Employers must share this responsibility by providing practical training to supplement the philosophical and theoretical base provided especially by university LIS education and training. LIS services employers are 
well placed to provide this aspect of the training, as it is in the work place that the latest trends and developments, especially information technology developments, manifest themselves.

2.6 Further studies among past students

While the majority of past students surveyed who were at the time of the study engaged in further studies, were registered for programmes/qualifications in the library and information science discipline, a significant number of these respondents were registered for programmes outside this discipline, particularly in commerce or business related disciplines. This as well as comments made by past students (for example, 'I have no ambition in my present profession' or 'I am looking for something more challenging to study') gives one the disturbing impression that some recent graduates and diplomates do not seem to feel very inspired and challenged in the LIS profession and are therefore opting for other fields. A further observation is that some recent graduates and diplomates are pursuing further studies in information related fields, for example, information management or information technology, but outside traditional library and/or information science departments. This is perhaps a reflection of the observation made in the literature (Broadbent 1985; Cronin 1985; Martin 1987; Lor 1990) that the information revolution along with the technology that is used to organise, process and disseminate information, has broken the monopoly that LIS departments or schools once had over the training of information professionals. Increasingly, computer science departments and business related academic departments are moving into this arena. In fact Crowley and Brace (1999) suggests that LIS departments' competition for students is likely to come from the latter and possible signs of this competition are reflected in findings in the study being reported here, where there seems to be a significant number of recent LIS diplomates and graduates opting for commerce or business related fields. Findings in the study also reflect the new trend at some universities of offering a three-year bachelor's degree with information related majors in an attempt to capture the emerging information markets by preparing graduates for the wider information field and not necessarily libraries. Some recent diplomates and graduates seem to be opting for these academic programmes, for example, B.A.(Information Science) or B.Com.(Informatics), in their further studies.

The preceding discussions have highlighted trends and issues in the findings of this study that reflect on the extent to which the various first level LIS programmes currently being offered in South Africa meet the job tasks or functions of posts that require the knowledge and skills that are generally imparted by first level LIS qualifications. There seems to be much commonality between employers and past students surveyed in the relevance ratings of modules in first level LIS programmes. A significant trend that emerges here is that modules that are applicable to all types of library and information environments are generally considered to be very relevant by employers and past students surveyed. This is a good indication that these are the types of modules that should form the 'core' of first level LIS programmes. Modules of a more specialist nature received relatively lower percentage relevance from both employers and past students with some of them suggesting that these should be made optional. This is an indication that such specialist modules are ideal for the elective aspects of first level LIS programmes giving students the opportunity to 'specialise' at the basic qualification level, and which has been encouraged in LIS education and training in South Africa (National Education Policy Investigation 1992; Van Brakel 1992; South African Institute for Librarianship and Information Science 1996). Modules of a more general nature and not directly relevant to the LIS services work environment were not considered by employers and past students to be very relevant. The author would like to be critical of both employers and past students here in that they take too narrow a view of these modules and fail to see their value in general education. Yet according to findings in the study, the majority of employers believe general education is essential for the provision of an efficient LIS service as it enhances delivery of service, makes people critical thinkers and benefits the LIS service in various other ways. The author thus believes that some employers and past students are being unwise in their suggestions for these general modules to be removed from or made optional in first level LIS programmes, especially technikon programmes which, unlike university LIS programmes, are generally lacking in general education. The author would also like to reiterate that while many suggestions have been forthcoming from employers, past students and even educators themselves for knowledge and skills that should be included in first level LIS programmes, it is not possible for LIS departments or programmes to accommodate all of these. Many of these knowledge and skills areas would need to be picked up through continuing education by the individual as well as through employer-led training programmes.

The same two research questions that had been generated to meet the first research objective (that is, to provide clarity to those currently employed in library and/or information services, those who wish to become library and/or information professionals and those who want to employ library and/or information professionals as to what type of first level education and training is required for given posts in the LIS services work environment) were required to meet the second research objective (that is, to provide clarity to library and/or information science educators regarding what job specifications they should be targeting in the academic curriculum, especially in view of the seemingly blurred demarcation between university and technikon library and/or information science education). Discussions above are 
relevant to the latter research objective as well. These discussions have highlighted trends and raised issues regarding findings in the study that relate to both university and technkon first level LIS programmes and qualifications. The author hopes that these discussions have gone some way in clarifying the distinction between university (professional) and technikon (paraprofessional) first level LIS qualifications so that LIS educators from each of these two types of higher educational institutions, that is, universities and technikons, have some idea on the type of job specifications they should be targeting in their academic curricula. Other discussions in the original study (for reasons of space these cannot be discussed here) offer further clarification on the relationship between university and technikon LIS education and training.

\section{Conclusions and recommendations}

The study confirms that the university Post-graduate Diploma in Library and/or Information Science and the B.Bibl. (or equivalent four-year university degree) are established professional LIS qualifications in South Africa. While the technikon ND: LIS is generally viewed as a paraprofessional qualification, LIS services employers are not using this qualification in its paraprofessional context, that is, as a parallel career path to professionalism for holders of this qualification, with its own post designations and career progressions separate from designations for clerical staff. However, at the same time employers are making use of the knowledge and skills of paraprofessionals. The current uncertainty regarding whether the technikon B.Tech.(LIS) should be regarded as a professional LIS qualification together with the four-year university LIS qualifications is largely the result of a general lack of clarity on the issue that professionalism and paraprofessionalism are alternative or parallel career paths each with its own career progression and that the latter is not a step in the direction of professionalism. The B.Tech.(LIS) is the next qualification level above the ND: LIS in the hierarchy of qualifications for the paraprofessional career path and therefore cannot be viewed as professional.

LIASA, like professional LIS bodies in the United States of America, Canada and Australia, should provide official recognition of the value and need for paraprofessionals in LIS services by, for example, creating a membership category for paraprofessionals as has happened in Australia. This is likely to influence LIS services employers to create career structures for paraprofessionals in their organisations.

Educators preparing LIS paraprofessionals for the LIS services market need to more vigorously market the paraprofessional qualifications among employers as qualifications whose incumbents have specific knowledge and skills and are able to occupy specifically designated paraprofessional posts.

LIS educators generally, need to make employers and students aware that LIS professionalism and paraprofessionalism are alternative career directions each with its own career progressions. Employers can be targeted on this issue via educator-employer liaison committees and advisory boards, workshops and the professional literature. Students may be enlightened on the fundamental difference between professionalism and paraprofessionalism by including this as a part of their curriculum.

Paraprofessional diplomates and graduates need to organise themselves into paraprofessional interest groups, staff associations, unions or any other structure that provides a forum for them to lobby for paraprofessional career structures in LIS services and to generally use these structures to further their interests and development as paraprofessionals.

Perhaps a further area of research should be an attempt to develop a LIS services work place model that tracks professional and paraprofessional career paths as parallel paths each with its own post designations and career progressions in an LIS service. Within these vertical parallel tracks individuals can aspire to climb as high as they wish to and/or their qualifications and/or experience allow them. Such a model would allow LIS professionalism and paraprofessionalism to be viewed as parallel career paths and not as one being inferior or superior to the other. Individuals in both tracks should be able to reach senior positions in LIS services organisations and with commensurate earnings. A model such as this would be of assistance to LIS services employers in developing staff structures that incorporate both professional and paraprofessional staff in a non-conflicting manner. At the same time the education system should allow for articulation between professionalism and paraprofessionalism giving one the opportunity to satisfy certain requirements before 'crossing over' to the 'other track' if one so desires.

\section{References}

American Library Association (ALA), Office for Accreditation. 1992. Standards for accreditation of master's program in library and information studies. Visited on 15/02/2002 at: http://www.ala.org/alaorg/oa/standard.html.

Babbie, E. 1990. Survey research methods. $2^{\text {nd }}$ ed. Belmont, California: Wadsworth.

Bowman, R.J. 1988. Library technicians under and over. Canadian library journal, 45(4):229-233.

Bramley, G. 1975. World trends in library education. London: Clive Bingley.

Broadbent, M. 1985. Trends in the educational preparation of library and information workers in Australia. In Armstrong, C. and Keenan, S. eds. Information technology in the library/information school curriculum : an international conference. pp. 73-82. Aldershot, England: Gower. 
Cronin, B. 1985. On the outside looking in... : issues in education for librarianship and information science. In Armstrong, C. and Keenan, S. eds. Information technology in the library/information school curriculum : an international conference. pp. 9-24. Aldershot, England: Gower.

Crowley, B. and Brace, B. 1999. A choice of futures : is it libraries versus information? American libraries, 30(4):76-77, 79.

Davidson-Arnott, F. and Kay, D. 1998. Library technician programs : skills-oriented paraprofessional education. Library trends, 46(3):540-562.

Dougherty, R.M. 1986. The underlying rationale. Library journal, I I I(3): I I8- I 20.

Durrheim, K. 1999. Quantitative analysis. In Terre Blanche, M. and Durrheim, K. eds. Research in practice : applied methods for the social sciences. pp. 96-122. Cape Town: University of Cape Town Press.

Froehlich, T.J. 1998. Ethical considerations regarding library non-professionals : competing perspectives and values. Library trends, 46(3): 444-466.

Gates, J.K. 1976. Introduction to librarianship. $2^{\text {nd }}$ ed. New York: McGraw Hill.

Gillen, E. 1995. To live and die an LA : career paths and professional development of the library assistant. In Battle, L.B. comp. From shelflist to database : resources, service, personnel : VLA paraprofessional forum : a program to enhance the professional development of paraprofessionals and to provide workshops, presentations, roundtables, panels and networking opportunities, 22 May 1995 - 23 May 1995. pp. 5-II. Richmond, Virginia: University of Richmond.

Halsted, D.D. and Neeley, D.M. 1990. The importance of the library technician. Library journal, I I 5(4):62-63.

Horton, W.J. 1990. The structure of the information profession in South Africa : the development of a rational pattern : inaugural lecture. Pietermaritzburg: University of Natal Press.

Hult, C.A. 1996. Researching and writing in the social sciences. Boston: Allyn and Bacon.

International Federation of Library Associations and Institutions (IFLA). 2000. Guidelines for professional library/information educational programs - 2000. Visited on 23/02/200I at: http://www.ifla.org/VII/s23/bulletin/guidelines.htm.

Johnson, I.M. 199I. The development of library technicians : a review of experience in selected countries. IFLA journal, I7(3): 256-265.

Kerkham, A.S. 1988. The education of library technicians in South Africa. South African journal of library and information science, 56(I): 7-10.

Lor, P. 1990. The future of education for library and information science in South Africa. In Nassimbeni, M. and de Jager, K. eds. The future of library and information science : social, technological and educational challenges : proceedings of the $50^{\text {th }}$ Anniversary Symposium of the School of Librarianship, University of Cape Town, 20-2I November 1989. pp. 67-82. Cape Town: University of Cape Town.

Martin, W.J. 1987. From library studies to information science. Education for information, 5: $129-137$.

Mugnier, C. 1980. The paraprofessional and the professional job structure. Chicago: American Library Association.

Musiker, R. 1986. Companion to South African libraries. Craighall: Ad. Donker.

National Education Policy Investigation (NEPI). 1992. Library and information services : report of the NEPI Library and Information Services Research Group : a project of the National Education Co-ordinating Committee. Cape Town: Oxford University Press.

Nettlefold, B.A. 1989. Paraprofessionalism in librarianship. International library review, 21 : 519-531.

Neuman, W.L. 1997. Social research methods : qualitative and quantitative approaches. $3^{\text {rd }}$ ed. Boston: Allyn and Bacon.

Oberg, L.R. 1991. Paraprofessionals : shaping the new reality. College and research libraries, 52(I): 3-4.

Oberg, L.R. 1992. The emergence of the paraprofessional in academic libraries : perceptions and realities. College and research libraries, 53(2): 99-। 12.

O'Brien, J. and Cowans, J. A. 1995. LTA world! : the next generation. Library administration and management, 9(I): 19-22.

Ocholla, D. 200I. Curriculum response to a changing national and international information environment : theoretical and methodological paradigms on review and revision. Education for information, 19: 143-167.

Quattrocchi, E. 1999. An outsider's thoughts on the education of librarians. American libraries, 30(4): 82-85.

Raju, J. 2002. First level library and/or information science qualifications at South African universities and technikons: a comparative study of curricula. PhD thesis, University of Natal, Pietermaritzburg.

Robbins, J.B. 1990. Yes Virginia, you can require an accredited master's degree for that job! Library journal, I I5(2): 40-44.

Rochester, M.K. 1997. Education for librarianship in Australia. London: Mansel.

Rodgers, T. 1997. The library paraprofessional : notes from the underground. Jefferson, N.C. ; London: McFarland.

Rosenberg, D. 1999. An overview of education for librarianship in Anglophone Sub-Saharan Africa. In Wise, M. ed. Education for librarianship and information science in Africa. pp. I I-33. Stockholm, Sweden: Uppsala University Library.

Shera, J.H. 1972. The foundations of education for librarianship. New York: Becker and Hayes.

South African Institute for Librarianship and Information Science (SAILIS). 1987. Standards for education for library and information science. Updated ed. s.I.: SAILIS.

South African Institute for Librarianship and Information Science (SAILIS). 1996. Proposed guidelines for undergraduate career training. s.I.: SAILIS.

Stieg, M.F. 1992. Change and challenge in library and information science education. Chicago ; London: ALA.

Underwood, P.G. and Nassimbeni, M.C. 1996. First steps : reconstructing library and information science education in South Africa. Education for information, 14: 215-223.

Van Aswegen, E.S. 1997. Menials or managers? : a decade of library and information science education at the Cape Technikon. South African journal of library and information science, 65(I): 53-59.

Van Brakel, P.A. 1992. Aspects regarding the educational structure of LIS training at South African universities. South African journal of library and information science, 60(3): 188-193.

Webb, G.M. 1988. Educating librarians and support staff for technical services. Journal of library administration, 9(I): I I I- I 20.

Wiegand, W.A. 1986. The socialisation of library and information science students : reflections on a century of formal education for librarianship. Library trends, 34(3): 383-399.

Wilson, A.M. and Hermanson, R. 1998. Educating and training library practitioners: a comparative history with trends and recommendations. Library trends, 46(3): 467-504. 